\title{
O SIGNIFICADO DE "RELAÇÕES HUMANAS"
}

LAERTE LEITE CORDEIRO

\begin{abstract}
Que atitude deve tomar o administrador, ao despertar para a importância das relações humanas na emprêsa ? Considerá-las panacéia para todos os males administrativos?
\end{abstract}

A grande dificuldade que se apresenta aos administradores interessados no problema das "relações humanas no trabalho" é que esta expressão quer dizer tanta coisa diferente, para tanta gente diferente, que ninguém mais tem certeza do que realmente significa. Há os que acham que relações humanas e relações industriais são a mesma coisa. Outros consideram relações humanas como administração de pessoal e outros há, ainda, que empregam relações públicas e relações humanas como sinônimos perfeitos. Aquêles que entendem as relações humanas como uma área de prática administrativa, muitas vêzes empregam a expressão para significar "passar a conversa", "adoçar a pípula", "levar o operário no bico" e por aí afora. Há, ainda, outros que entendem por relações humanas a "arte de fazer amigos e influenciar pessoas".

Poderíamos prosseguir neste trabalho e arrolar outros significados emprestados atualmente à expressão "relações humanas", porém aquêles que mencionamos são talvez os mais representativos do conjunto e bastam para demonstrar a confusão reinante em tôrno da matéria.

LAERTE LEITE CORDEIRO - Professor-Adjunto, Departamento de Administração Geral e Relações Industriais e Conselheiro para o Centro Acadêmico da Escola de Administração de Emprêsas de São Paulo. 
Nesta nossa discussão, tentaremos trazer alguma luz a êste assunto tão controvertido, com o objetivo de oferecer um subsídio aos administradores que, na prática, se defrontam, a todo instante, com problemas que são eminentemente humanos e que requerem, para sua solução, uma compreensão correta do significado e das implicações das relações entre os. sêres humanos no ambiente de trabalho.

\section{Retrospecto Histórico}

Embora as relações humanas tenham existido desde os primórdios da vida humana, a preocupação científica com essas. relações, no ambiente de trabalho, é relativamente nova. Nos. Estados Unidos, até 1940, a expressão "relações humanas no trabalho" era muito pouco usada (1) e o PROF. MÁRIO WAGNER. VIEIRA DA CUNHA nos diz que, em 1945, ao findar a Segunda Grande Guerra, a mesma era pràticamente ignorada entre nós (2).

Se pudéssemos, fazendo voltar os ponteiros do relógio no. tempo, observar o desenrolar dos acontecimentos no início da Revolução Industrial, veríamos que, então, os sêres humanos. eram incluídos no processo de produção apenas como mais um recurso produtivo, ao lado das matérias-primas e das máquinas, sem qualquer consideração especial. Em outras palavras, o homem nada mais era do que uma máquina que operava outra máquina. A medida que as organizações industriais se desenvolviam, mais se perdia a possibilidade de contato pessoal direto entre o trabalhador e seu empregador. A ênfase, naquele momento, era colocada sôbre a produção, com um conseqüente desinterêsse pela sorte do trabalhador. Este, então, era obrigado a trabalhar longas horas, em condições desfavoráveis e sob padrões de supervisão tão rígidos e rigorosos que quase não podia manter contato informal com seus. colegas. Na maioria dos casos, êsse contato humano ocorria fora do ambiente de trabalho, porém, ainda assim, limitado pelas longas horas de atividade na fábrica.

(1) Keith Davis, Human Relations in Business, McGraw-Hill Book Company, New York, N. Y., 1957, pg. 5.

(2) Mario Wagner Vieira da Cunha, «A Ideologia das Relações Humanas na Indústria» em Problemas Psicóógicos da Indústria, Editado pelo Serviço de Publicações da FIESP e CIESP, 1959, pg. 87. 
E KEITH DAVIS quem nos fala do aparecimento, nesse momento da História, de dois homens que representaram uma filosofia pioneira, na consideração do fator humano no esfôrço de produção: ROBERT OWEN E ANDREW URE (3). OWEN, um industrial galês, foi talvez o primeiro homem de emprêsa a se preocupar, por volta do ano de 1800 , com o problema das necessidades dos trabalhadores. $O$ segundo, ANDREW URE, publicc"1, em 1835, um livro intitulado a "Filosofia da Indústria", no qual apontava aos industriais da época o fator humano como merecedor de considerações especiais, devido a sua importância para o processo produtivo.

As idéias dêsses dois pioneiros tiveram fria acolhida na época e, na maioria dos casos, descambou-se para um paternalismo exagerado, ao invés de chegar-se a um reconhecimento sadio e genuíno da importância dos trabalhadores em relação à produção. Embora fôsse possível notar alguns esforços isolados, na direção de dar maior relevância ao fator humano no trabalho, a verdade é que os rápidos progressos, nas ciências físicas, feitos nos séculos imediatamente anteriores a êste desviaram a preocupação científica com os problemas humanos para outros mais materiais.

Sòmente no início dêste nosso século é que se pôde notar um nôvo esfôrço no sentido de olhar para o homem como fator importante na indústria. Nesse momento, surge o americano FREDERICK WINSLOW TAYLOR, hoje chamado de "o pioneiro da organização racional do trabalho". Sua contribuição ao campo das relações humanas no trabalho é relevante, por ter sido êle o primeiro a chamar a atenção para os sêres humanos no trabalho como fatôres importante para a eficiência da produção. A preocupação de TAYLOR, na época, era dirigida para a produção e sua consideração para com o fator humano prendia-se apenas a sua produtividade, no sentido da racionalização e eficiência do processo produtivo. Contudo, se bem que seu objetivo fôsse diferente, as inovações que introduziu na administração abriram o caminho para as posteriores contribuições ao campo das relações humanas no trabalho.

(3) Keith Davis, op. cit., pgs. 5-6. 


\section{A Fase Contemporânea}

Em 1924, um grupo de pesquisadores, chefiado pelo psicólogo GEORGE ELTON MAYO, dava início, na fábrica "Hawthorne", da "Companhia Western Electric", em Chicago, a uma pesquisa que visava estudar a relação entre a eficiência do trabalhador e a iluminação no ambiente de trabalho. As premissas sôbre as quais se baseava esta pesquisa eram ainda as mesmas da época de TAYLOR, o que vale dizer que se supunha : (1..$^{\circ}$ que os trabalhadores deviam ser estudados como unidade isolada; $\left(2 .^{\circ}\right)$ que, em muitos aspectos, o trabalhador era uma máquina cuja eficiência podia ser cientîficamente estimada; e $\left(3 .^{\circ}\right)$ que os fatôres que influenciavam sua eficiência eram o mau contrôle dos seus movimentos ao executar a tarefa, a fadiga e as más condições de trabalho. Leve-se em conta, também, que todo o incentivo oferecido aos trabalhadores, na época, girava em tôrno de recompensas monetárias, uma vez que a premissa era a de que, no trabalho, o homem buscava apenas a satisfação de sua necessidade econômica.

Para essa pesquisa, cuja hipótese era a de que quanto melhor a iluminação no ambiente melhor o trabalho, escolheram-se dois grupos de operários: o grupo de contrôle e o grupo experimental. Num dêles, - o de contrôle - a iluminação mantinha-se inalterada durante todo o experimento, ao passo que, no outro, a iluminação aumentava em intensidade. Como era esperado pelos pesquisadores, a produção do grupo experimental aumentou. Aconteceu, porém, que, no grupo de contrôle onde a iluminação tinha sido mantida, a produção também aumentou. Este resultado inicial foi, naturalmente, incompreensível para os investigadores, que decidiram, então, reduzir a intensidade da iluminação para o grupo experimental, a fim de ver o que acontecia. Resultou que a produção, ainda uma vez, aumentou. A conclusão a que chegaram os pesquisadores foi a de que, òbviamente, algum outro fator não controlado e não previsto atuava sôbre os grupos, fazendo com que a produção aumentasse, independentemente da maior ou menor intensidade da luz no ambiente de trabalho.

O grupo de pesquisadores concluiu, então, pela necessidade de um nôvo experimento para descobrir qual a natureza do 
fator desconhecido. Foram selecionadas duas operárias, a quem se pediu que escolhessem outras quatro, compondo um pequeno grupo de seis môças. Sua tarefa era a de montar peças para aparelhos telefônicos. Foram separadas das demais operárias, passando a trabalhar numa sala especial, com um observador que permanecia entre elas anotando tudo o que acontecia, dando e pedindo informações sôbre o desenvolvimento do experimento e ouvindo suas queixas. A pesquisa foi realizada com a introdução de várias modificações na situação de trabalho das môças. O ponto de partida era o seguinte: sob condições normais, com 48 horas semanais de trabalho - sábados inclusive - e sem pausas para descanso durante o dia, cada môça produzia 2.400 peças por semana. BROWN nos descreve, resumidamente, a experiência e seus resultados : (4)

I - Introduzem-se duas pausas para descanso : 5 minutos pela manhã e 5 minutos à tarde. A produção aumenta.

II - As pausas passam a ser de 10 minutos. Nôvo aumento na produção.

III - Seis pausas de 5 minutos são introduzidas. A produção cai, tendo as môças reclamado que o ritmo de trabalho estava sendo prejudicado pelas pausas frequientes.

IV - Volta-se às duas pausas anteriores, oferecendo-se, em adição, uma refeição quente, grátis. A produção volta a subir.

$\mathrm{V}$ - Permite-se às môças saírem meia hora mais cedo. A produção sobe ainda mais.

VI - Outra meia hora é suprimida. A produção permanece estável.

VII - Suprime-se o trabalho aos sábados. A produção novamente aumenta.

VIII - Tôdas as concessões são suprimidas, tendo as môças voltado a trabalhar exatamente nas mesmas condições do comêço do experimento, isto

(4) J. A. C. Brown, The Social Psychology of Industry, Penguin Books Ltd., Harmondeworth, Middlesex, Inglaterra, 1954, pgs. $70-72$. 
é, 48 horas semanais, sem pausas para descanso e sem refeição quente gratuita. Resultado: A produção bate todos os recordes, assinalando 3.000 peças por semana para cada operária.

STUART CHASE, conceituado autor americano, é quem oferece, em nosso entender, a melhor contribuição para explicar os resultados desta pesquisa. Diz êle que "em se solicitando o auxílio e a cooperação das môças para o experimento, os pesquisadores fizeram com que elas se sentissem importantes. Deixaram de sentir-se como peças de uma máquina para se colocarem na posição de um grupo coeso que tentava ajudar a companhia a resolver um problema. Encontraram estabilidade, um grupo ao qual sentiam pertencer e um trabalho cujo objetivo podiam claramente perceber. Devido a isso, trabalharam mais e melhor de que em qualquer época de suas vidas" (5).

O grupo dirigido por ELTON MAYo passou vários anos pesquisando o trabalho humano na fábrica "Hawthorne" e os resultados das várias pesquisas levadas a efeito foram amplamente divulgados, não cabendo, nesta nossa breve apreciação histórica, o seu exame mais minucioso (6). Podemos, porém, resumir suas conclusões genèricamente, para dizer que as experiências realizadas mostraram que o operário não era uma simples peça do processo, mas sim um indivíduo com uma personalidade complexa, relacionando-se com os demais numa situação de grupo, motivado não só pela busca do confôrto material, mas também por necessidades de natureza social e psicológica.

Desta breve investigação a respeito dos sêres humanos no trabalho deduzimos que a História se divide, grosso modo, em três grandes fases:

$1 .^{\circ}$ - O Homem existindo apenas como um recurso produtivo ao lado das matérias-primas e das ráquinas, sem nenhuma consideração especial. (Fase em que aparecem oWEN e URE).

(5) Stuart Chase, Men at Work, Harcourt, 1945.

(6) F. J. Roethlisberger e W. J. Dickson, Management and the Worker Harvard University Press, 1939. 
$2 .^{\circ}$ - O Homem como uma peça extremamente importante para o processo de produção, motivado o seu comportamento pela busca da satisfação de suas necessidades materiais (fase de TAYLOR).

3. - O Homem como mais do que uma simples peça de processo produtivo, merecedor de considerações especiais, motivado o seu comportamento não só pela necessidade de satisfazer seus desejos materiais, como também pela busca constante da satisfação de suas necessidades sociais e psicológicas. (Fase iniciada por ELTON MAYO e seus colaboradores).

Esta última fase é contemporânea, pois as pesquisas de Mayo e seus colegas foram o ponto de partida para um grande número de outras pesquisas, na área de estudo do fator humano no trabalho, e chamaram a atenção dos homens de emprêsa e dos estudiosos para o que hoje conhecemos como "relações humanas no trabalho".

\section{O Significado de "Relações Humanas"}

A expressão "relações humanas" significa, literalmente, o estabelecimento e/ou a manutenção de contatos entre sêres humanos (7). Como tal, ocorrem, diária e freqüentemente, na vida de todos nós. Acontecem em casa, com a nossa espôsa e nossos filhos; no clube, quando integramos a nossa valorosa equipe de futebol; no bar da esquina, com o rapaz que nos serve um refresco no dia de calor; no ônibus, com o cobrador a quem pagamos a passagem; e, principalmente, no ambiente de trabalho - onde passamos a maior parte de nosso tempo útil —, com nossos colegas, superiores e subordinados. Temos, então, que, no seu sentido estritamente literal, a expressão "relações humanas" quer dizer todos aquêles contatos entre os sêres humanos que se processam em tôdas as situações.

17) Anibal Bonfim, «Relações Humanas», em Arquivos Brasileiros de Psicotécnica, junho 1954 , ano $6, \mathrm{n} .^{\circ} 2, \mathrm{pg} .71$. 
Porém, paralelamente ao significado literal, surgiu um outro significado para a expressão "relações humanas", que é mais amplo do que o primeiro. Modernamente, entende-se por relações humanas uma atitude que deve prevalecer no estabelecimento e na manutenção dos contatos entre pessoas. Essa atitude deve estar assentada no princípio do reconhecimento dos sêres humanos como entes possuidores de uma personalidade própria que merece ser respeitada. Isso implica numa compreensão sadia de que tôda pessoa traz consigo, em tôdas as situações, necessidades materiais, sociais e psicológicas que procura satisfazer e que dirigem seu comportamento neste ou naquele sentido. Assim como as pessoas são diferentes entre si, também a composição e estrutura das necessidades variam de indivíduo para indivíduo.

Praticar relações humanas significa, portanto, muito mais do que estabelecermos e/ou mantermos contatos com outros indivíduos. Significa estarmos condicionados, nessas nossas relações, por uma atitude, um estado de espírito ou uma maneira de ver as coisas, que nos permita compreender o nosso interlocutor, respeitando a sua personalidade, cuja estrutura é, sem dúvida, diferente da nossa. Isto quer dizer que praticar relações humanas não equivale simplesmente a "amar ao próximo como a nós mesmos" pois o que é bom para uns não é necessàriamente válido para outros, em decorrência das diferenças de composição e estrutura de suas necessidades.

De acôrdo com êsse significado mais amplo, podemos dizer que, onde quer que se estabeleçam e/ou mantenham contatos entre pessoas, poderá ou não estar presente aquela atitude que chamamos de "relações humanas". Na ausência dessa atitude, o que resulta é um clima de ressentimento, resistência, incompreensão, falta de colaboração e iniciativa, enfim, uma atmosfera que não conduz a um aproveitamento positivo na relação que se estabelece. É nesse momento que, por vêzes, temos as nossas "brigas" com a espôsa, somos mal servidos no restaurante, discutimos com o inquilino do andar de cima e perdemos a boa vontade e a cooperação espontânea de nossos subordinados. 
Se, por outro lado, se manifesta a prática de relações humanas, então podemos afirmar, sem mêdo de errar, que o contato humano que se estabelece tenderá para um resultado positivo, eliminando, "a priori", a possibilidade de conflito básico entre as partes, dando a cada uma um crédito preliminar que facilitará o desenvolvimento da relação.

E nossa intenção, nesta discussão genérica do significado do têrmo, deixar claro que a conceituação atual de relações humanas se aplica a qualquer situação. Êsse fato é fàcilmente constatável através de uma análise sumária da variedade terminológica que se pode observar na literatura, nos artigos de jornais, nas revistas especializadas, nas conferências e em outros meios de divulgação, atribuindo um qualificativo a essa expressão genérica. Encontramos, então, relações humanas "na família", "na indústria", "para vendedores", "na escola", "no trabalho" e assim por diante, refletindo uma preocupação atual e geral pelo aspecto positivo das relações entre pessoas.

Para efeito dêste artigo, todavia, nosso interêsse é mais restrito, pois nos permitimos afirmar, ao início, que tentaríamos oferecer um subsídio aos administradores, no sentido de uma compreensão mais ampla do significado das relações humanas no trabalho. Assim, além dos comentários genéricos que intentamos, vale dizer que tôdas as pesquisas realizadas nesse campo, a partir de MAYo, nos levam a concluir que, nas, suas atitudes para com os demais membros da organização, os administradores deverão sempre reconhecer que cada um de seus colegas, chefes e subordinados, mais do que o simples executor de uma tarefa específica, é um ser humano, e que embora fôsse desejável - por vêzes - que os indivíduos, na organização, se comportassem única e exclusivamente de acôrdo com a "nossa" lógica e com os "nossos" padrões de expectativa, isso nem sempre acontece, pois os sentimentos, a sensibilidade e as emoções são qualidades inerentes aos sêres humanos, das quais não se desvestem ao entrar no escritório, na fábrica ou na loja.

Cabe ao administrador, cujo poder de decisão influencia e orienta o sentido das relações entre os indivíduos, na organização, estabelecer um clima positivo e favorável para que 
a emprêsa possa contar com um ponto de apoio para a realização e execução de suas funções essenciais. Essa tarefa superlativa que se espera seja executada em todos os níveis de supervisão só poderá ser levada a cabo se os próprios administradores estiverem condicionados pela atitude que aqui chamamos de "relações humanas".

As emprêsas cabe a formulação e o estabelecimento de diretrizes administrativas que traduzam uma preocupação com o clima de relações humanas que deve permear a organização, a fim de que seus objetivos possam ser alcançados ao mesmo tempo que se promove, tanto quanto possível, a satisfação das necessidades de seus membros.

\section{Eliminando a Confusão}

Cabe-nos, agora, tentar eliminar algumas das confusões que mencionamos ao início dêste trabalho e aquelas que mais frequientemente lemos, ouvimos e vimos, no decorrer dos nossos contatos com a literatura, com os jornais, com muitos administradores e com muitas emprêsas.

\section{A - Relações Humanas e Relações Industriais.}

Relações Industriais é uma função dentro da estrutura organizacional que tem, por objetivo, "planejar, encaminhar e integrar os recursos humanos da emprêsa" (8). Inclui a administração de pessoal e vai além, estabelecendo programas de treinamento, mantendo ambulatórios médicos, operando restaurantes, publicando o jornal da emprêsa, etc. . E o departamento, a divisão ou o serviço ao qual cabe implementar as diretrizes de relações humanas formuladas pela emprêsa, quer cuidando da satisfação das necessidades materiais dos membros da organização, quer treinando êsses membros - principalmente os supervisores dos vários níveis - para a prática de relações humanas no trabalho. Em muitas emprêsas, infelizmente, o departamento de relações industriais é considerado como o departamento "quebra-galho", pois sòmente depois que o conflito se estabeleceu entre as pessoas se corre ao médico, na esperança de que, aplicando o remédio "re-

(8) Dalton E. McFarland, Management, Principles and Pratices, McGraw-Hill Book Company, New York, N. Y., 1958, pg. 356. 
lações humanas", o paciente melhore. O problema que se coloca para êsse departamento é que "relações humanas", em geral, é, antes de tudo, uma vacina.

Cabe aqui observar, resumindo, que relações industriais é uma função definida dentro da estrutura da organização da emprêsa e que, portanto, difere de relações humanas, que se traduz numa atitude que deve condicionar os membros da organização nas suas inter-relações pessoais. Não se deve ainda confundir relações humanas com administração de pessoal, uma vez que esta função se refere principalmente aos problemas de seleção, colocação, avaliação e contrôle dos empregados.

\section{B - Relações Humanas e Relações Públicas}

Esta é, provàvelmente, a confusão mais generalizada. Devemos, antes de mais nada, definir relações públicas : "é o processo contínuo através do qual a emprêsa, como entidade, procura obter e manter a boa vontade e a compreensão de seus fregueses, dos seus empregados e do público, em geral" (9).

A preocupação básica na execução desta função, como vemos, é criar uma imagem favorável da emprêsa perante os vários "públicos" com quem ela se relaciona. Seria possível, tomando-se para esta expressão um sentido ultra amplo, que a preocupação com as relações humanas no trabalho estivesse nela incluída. Porém, na prática, as relações públicas significam mais esfôrço funcional para divulgar do que implementar a atitude de relações humanas. Não nos esqueçamos ainda que, para efeito de relações públicas, os membros da organização constituem-se em apenas um dos muitos "públicos" da emprêsa.

\section{C - Relações Humanas como Artifício de Manipulação}

"Levar os outros no bico", "adoçar a pílula" e "passar a conversa" são, para alguns, a aplicação das técnicas (sic) de relações humanas. Quando se tenta manipular o indivíduo, explo-

(9) Bertrand R. Canfield, Public Relations, Richard D. Irwin, Inc., Homewood, Illinois, 1956, Ed. Revista, pg. 19. 
rando seus sentimentos para um fim que é apenas nosso, não é "relações humanas" que estamos praticando, mas sim manipulação, no sentido mais deplorável da palavra. 0 exemplo clássico é o do administrador que finge estar interessado nos seus subordinados e nas suas sugestões, mas sòmente para disfarçar a sua atitude essencialmente autoritária. Porém, a maioria das pessoas descobre fàcilmente quando há ou não sinceridade na atitude expressa e, então, a situação se torna muito mais difícil, pois, além da resistência lógica que poderiam oferecer, as pessoas ressentem-se ainda da má fé envolvida na tentativa de manipulação. As relações humanas presumem uma atitude que envolve uma compreensão mútua e sincera dos sentimentos e anseios que todo ser humano leva consigo.

\section{D - Relações Humanas e a "Arte de Fazer Amigos"}

Já tivemos a oportunidade, por vêzes, de perceber que existem administradores que entendem relações humanas como uma "arte de fazer amigos". Um sorriso sempre plantado na face, memorização forçada dos nomes dos funcionários e "tapinhas" generalizados nas costas de todo mundo são algumas das obrigações a que se comprometem êsses administradores. Não queremos aqui negar o mérito dêstes comportamentos recomendados por muitos. É preciso deixar bem claro, todavia, que se usados apenas como artifícios, sem uma atitude correspondente que lhes empreste autenticidade e sinceridade, de nada valerão.

Da prática de relações humanas deve fluir, necessàriamente, um comportamento natural e sincero que não implica em ser "bonzinho", paternal ou sorridente a todo instante. A emprêsa tem seus objetivos a alcançar e, no cumprimento de suas funções, o administrador não tem por meta fundamental "fazer amigos", mas sim providenciar para a execução do trabalho. Claro está que, em criando um clima saudável de relações humanas, êsse objetivo poderá ser alcançado com mais facilidade. Ainda assim, porém, haverá momentos nos quais, mesmo condicionado por essa atitude, o administrador terá que responsabilizar pessoalmente êste ou aquêle subordinado, tomar decisões práticas e objetivas e "botar na rua quem não presta". 


\section{Conclusões}

Para resumir esta discussão sôbre o significado de relações humanas, queremos, uma vez mais, insistir em que falamos da atitude de reconhecimento dos indivíduos como sêres humanos, na sua mais ampla acepção, que deve condicionar os administradores nas suas relações com os demais membros. da organização e nas suas decisões administrativas:

Assim, "relações humanas" não pode ser compreendida como uma função a ser executada, como um artifício de manipulação ou maneira de tornar todos felizes e contentes. Na emprêsa, as relações humanas agem como um lubrificante, evitando os atritos e tornando o funcionamento mais suave. Nada mais. Mas, assim como uma máquina não funciona apenas com uma boa lubrificação, a emprêsa precisa de muitas. coisas, além de relações humanas.

Não se pretende assim, que estas sejam um substituto para as demais funções do administrador. "Relações humanas" não é pois, uma panacéia que, por si só, cure todos os males. 